\title{
Near field modelling of dust emissions caused by drilling and crushing
}

\author{
M. Sairanen ${ }^{1}(1) \cdot$ S. Pursio ${ }^{2}$
}

Received: 1 March 2020 / Accepted: 28 May 2020 / Published online: 9 June 2020

(c) The Author(s) $2020 \quad$ OPEN

\begin{abstract}
This study compares modelling results to measured concentrations near dust sources in a natural stone quarry and in two aggregate quarries. In the natural stone quarry, the dust source was drilling and in the aggregate quarries, it was crushing. Aim is to evaluate performance of model BREEZE AERMOD under $200 \mathrm{~m}$ from the dust source, and to estimate AERMOD's applicability to represent short time dust dispersion events. If the model can capture the short-term variation of dust dispersion, it is usable in evaluation of weather conditions, when dust prevention should be enhanced, or production even paused, if there are critical objects near the quarry. The comparison between the measured and the modelled concentrations showed, that the model reacted more severely to changes in weather conditions, whereas the measurements showed no significant changes. AERMOD was not able to predict hourly concentration fluctuation, which is assumed to result from the lack of on-site meteorological data. The emission factors (EFs) determined for drilling either overestimated or underestimated the dust concentration. Therefore, the EF for drilling needs further research to obtain results reflecting the measured concentration levels better. The EF for crushing predicted well the dust dispersion near the dust source during the summer, but the model was unable to predict the dust concentration increase during the wintertime caused by the ground inversion, trapping the dust particles to remain near the ground. Modelling is applicable to aggregate quarries operating during unstable (non-inversion) meteorological conditions. Usage of on-site weather parameters is recommended.
\end{abstract}

Keywords Crushing $\cdot$ Drilling $\cdot$ Modelling $\cdot$ Open-pit quarry $\cdot \mathrm{PM}_{10}$

\section{Introduction}

Dust is an environmental issue at many quarries and crushing is the most significant source of it [1, 2]. According to Sairanen and Selonen [3] drilling is the most dust producing activity in natural stone quarries. Aggregate production is reported to generate mainly coarse $\left(\mathrm{PM}_{10}\right.$ or larger) particles $[4,5]$, whereas the majority of the dust generated during the drilling is $\mathrm{PM}_{10}$ [3]. $\mathrm{PM}_{10}$ is particle passing through a size-selective inlet with a $50 \%$ efficiency cut-off at $10 \mu \mathrm{m}$ aerodynamic diameter [6]. Large particles will deposit within few hundred of meters from the dust source, while particles of an intermediate size range $(10-30 \mu \mathrm{m})$ are likely to travel up to $200-500 \mathrm{~m}$ [4].

Dust measurements in real operating conditions are demanding due to a large number of variables affecting the spreading of the dust. The weather conditions, especially the wind direction, have a crucial impact on dust dispersion. Dispersion modelling uses mathematical equations, describing the atmosphere, the dispersion, and the physical processes within the plume, to calculate concentrations at various locations [7]. In this study modelling

Electronic supplementary material The online version of this article (https://doi.org/10.1007/s42452-020-2976-9) contains supplementary material, which is available to authorized users.

M. Sairanen, marjo.sairanen@gmail.com; S. Pursio, saku.pursio@metso.com | 'Department of Civil Engineering, Aalto University, 00076 Espoo, Finland. ${ }^{2}$ Aggregates Technology, Metso Minerals, 33101 Tampere, Finland. 
is used to assess the dust dispersion in the vicinity of a quarry. Estimation of the dust fall out is important when evaluating the dust dispersion of a future quarry.

Sivacoumar et al. [8] performed calculations with FDM, ISCST3, and BREEZE AERMOD softwares to assess dust emission from an aggregate crushing station and compared the results with measured dust concentrations. Sivacoumar et al. [8] determined impact zones for total suspended solids (TSP) and $\mathrm{PM}_{10}$ by defining a constant concentration contour of $200 \mu \mathrm{g} \mathrm{TSP} / \mathrm{m}^{3}$ and $100 \mu \mathrm{g}$ $\mathrm{PM}_{10} / \mathrm{m}^{3}$. The impact zone for measured concentrations varied between 211 and $1350 \mathrm{~m}$ with a mean of $784 \mathrm{~m}$. The impact zone according to the FDM model suggested spreading of the dust between 153 and $2650 \mathrm{~m}$ from the source with a mean of $1335 \mathrm{~m}$. Respectively, the ISCST3 model suggested spreading of the dust between 43 and $1056 \mathrm{~m}$ with a mean of $501 \mathrm{~m}$, and the BREEZE AERMOD model between 135 and $1225 \mathrm{~m}$ with a mean of $679 \mathrm{~m}$ [8].

Tartakovsky et al. [9] evaluated the performance of models BREEZE AERMOD and CALPUFF to predict TSP concentrations from a quarry locating in a complex topography. BREEZE AERMOD calculations resulted in a better agreement with measurements compared to results obtained from CALPUFF: BREEZE AERMOD TSP estimates were, on average, $42-81 \%$ of the measured concentrations, whereas the CALPUFF average TSP estimates were only $16-18 \%$ of the measured concentrations [9]. The evaluation between these two models was continued by Tartakovsky et al. [10]. They used both observational and WRF-modelled (weather research and forecasting model) meteorological data in modelling when they compared modelled TSP and $\mathrm{PM}_{10}$ concentrations to measured ones. Again, BREEZE AERMOD was found to predict more accurately the ambient TSP and $\mathrm{PM}_{10}$ concentrations compared to CALPUFF. Nevertheless, the performance of both models (BREEZE AERMOD and CALPUFF), using either meteorological measurements or the WRF-modelled wind field, was low [10].

According to Venkatram et al. [11], dispersion models commonly used for regulatory applications generally underestimate the lower range of pollutant concentrations and overestimate the high pollutant concentrations in near-field of the dust source. BREEZE AERMOD was shown to provide reliable near-field concentration estimates from urban emission sources if turbulent velocity measurements close to a source were used to estimate the plume dispersion [11].

Modelling of dust dispersion is an important tool when evaluating environmental effects of a future quarry and authorities may demand modelling when applying permits for quarrying. Therefore, it is essential, that modelling represents well the actual circumstances. Modelling and measurements have been compared in some studies [e.g. previously mentioned 8-10], but none of them deals with the behaviour of dust dispersion at short distances (hundred meters or less) and short time period (like hours). Complaints of dust from a quarry spreading into the neighbourhood appear near the quarries, mainly within few hundreds of meters, and complaints concern certain days or even a time of the day. Therefore, the usually modelled situation of yearly concentration averages does not represent well the situation experienced in the nearby residential areas.

This study compares modelling results to measured concentrations near dust sources in a natural stone quarry and in two aggregate quarries. The aim is to evaluate the model performance within the quarry boundary under $200 \mathrm{~m}$ from the dust source. Another target is to estimate the model's applicability to represent short time dust dispersion events, which can cause complaints in the nearby neighbourhood. If the model can capture the short-term variation of dust dispersion, it could be used to evaluate the weather conditions, when dust prevention should be enhanced, or production even paused, if there are critical objects in the area near the quarry.

\section{Dust measurements}

This study deals with results from one natural stone quarry and three aggregate quarries. Dust measurements results from the natural stone quarry and from one of the aggregate quarries were made and reported previously by Sairanen and Selonen [3] and Sairanen and Rinne [5], respectively. Two additional aggregate quarries were measured for this study.

\subsection{Previously made dust measurements}

Dust measurements reported previously have been made in two natural stone quarries denoted $A$ and $B$ [3] and in six aggregate quarries denoted 1 to 6 [5]. From the previous site measurements, the results having the most measurement locations at downwind (DW) were selected to be tested in this study via modelling. These were quarry $B$ with horizontal drilling and crushing in aggregate quarry 5. Detailed information of the quarries and their dust sources from the previously reported studies, used in this modelling study, are presented in Table 1.

\subsection{Dust measurements made in this study}

In addition, measurements from two other aggregate quarries are reported in this study: Aggregate quarries 7 and 8 (see Table 1). These measurement results are also compared with modelled concentrations. Measurements 


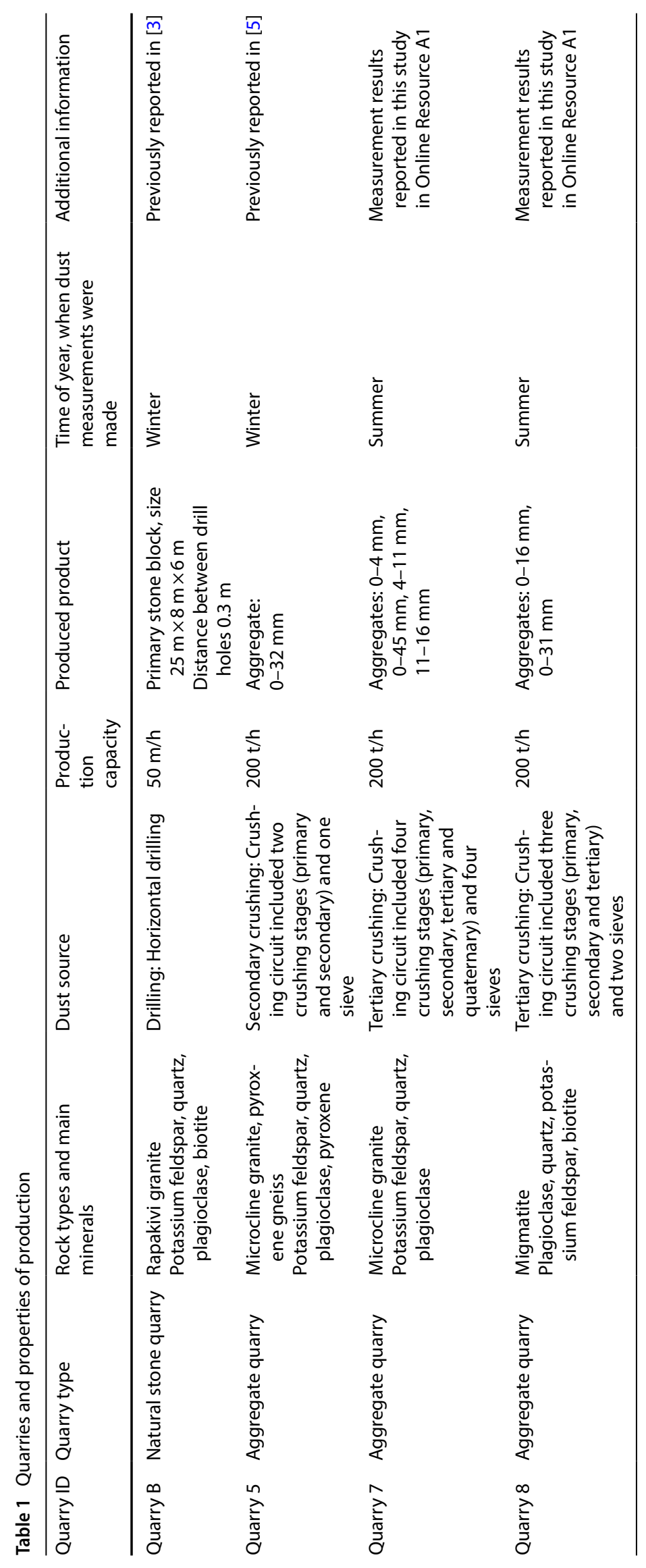


in quarries 7 and 8 were made with the same study set-up as the previously reported ones. Dust measurements were made with the Turnkey Osiris nephelometer, which measures four particle sizes (TSP, $\mathrm{PM}_{10}, \mathrm{PM}_{2.5}$ and $\mathrm{PM}_{1}$ ) at the same time. The dust measurement set-up and the results from measurements are presented in more detail in the Online Resource A1.

In the quarries 7 and 8 , the measurements were made during the summer, whereas all previously reported measurements (natural stone quarries $A, B$ and aggregate quarries 1 to 6) were made during the winter. Detailed information of quarries and their dust sources measured and modelled in this study are presented in Table 1.

\section{Model set-up}

\subsection{Applied modelling program and emission factors}

Used software was BREEZE AERMOD version 8.0.0.39 (from now on AERMOD). AERMOD was the chosen model evaluated in this study, since it is accepted for modelling particle dispersion by environmental authorities [e.g. 12]. In addition, AERMOD has been previously reported to perform adequately, while modelling dust emissions from the open-pit quarries [e.g. 8, 9].

Following default settings were applied in the model:

- Particle dry depletion was enabled

- No seasonal variation in emission factor (EF) were applied, e.g. EF was one-fold during all seasons i.e. winter, spring, summer, and autumn

- Background concentration was not added into the modelled results

- Default wind speed categories were used

- Model run was optimized

The height of the flagpole receptor was $1.5 \mathrm{~m}$, which is the same as the sampling probe height in the corresponding site measurements.

Drilling was modelled as a point source. Dust from drilling is spread from a small area hence the point source assumption is valid. Model demands the knowledge of a stack diameter and the speed of the gas/air in the stack, when modelling point source. The diameter of the drilled hole and the velocity of the drilling were used, since the dust comes out from the drill hole, and the speed of the drilling is assumed to be proportional to the speed of the dust spreading into the atmosphere.

Crushing was modelled as a volume source, which is assumed to have a rectangular shape in AERMOD. Crushing circuits were approximately $30 \mathrm{~m}$ long and 5-15 m wide. Therefore, the crusher in the model was constructed as two volume sources, both having an area of $10 \mathrm{~m} \times 10 \mathrm{~m}$, locating $10 \mathrm{~m}$ apart from each other.

An EF relates to the quantity of a pollutant released to the atmosphere from the source. US EPA [13] has determined the EFs for various phases of quarrying and they are commonly applied, when modelling dust dispersion for regulatory purposes. Therefore, the EFs of US EPA [13] were used in this study.

US EPA [13] defines the EF only for wet drilling. Since the natural stone quarry $B$, applied dry drilling, the EF for dry drilling determined by Aatos [14] was also used in modelling. The lower and upper end of the EF range for dry drilling was applied in this study.

Quarrying produces mainly coarse $\left(\mathrm{PM}_{10}\right.$ or larger) particles and EFs are more widely available for $\mathrm{PM}_{10}$ than for TSP. Therefore, the modelling was made for size fraction $\mathrm{PM}_{10}$. $\mathrm{PM}_{10}$ also has limit values in legislation, e.g. in U.S. and $\mathrm{EU}$ region.

US EPA [13] determines the EFs in form of $\mathrm{kg} / \mathrm{t}$, whereas AERMOD uses the EFs in form of $\mathrm{g} / \mathrm{s}$. The announced capacities of the measured drill and crushers were used, when transforming the EF into the unit demanded by the AERMOD. Aatos [14] had defined EF in the form of $\mathrm{g} / \mathrm{s}$.

The detailed information used in the calculation of the EFs, and the EFs used in the modelling are presented in Table 2. Since the modelled concentrations from the quarry 8 were zero, it is omitted from further consideration.

In both modelled aggregate quarries 5 and 7, the EF of tertiary crushing was applied, since no other EF for crushing is defined by US EPA [13]. The EFs for sieving and conveying were taken into account according to the number of sieves and conveyors in operation during the dust measurements. In the quarry 5 , the crusher was secondary crusher, i.e. the crushing circuit included two crushing stages, one sieve, and one conveyor. In the quarry 7 , the crushing circuit applied four crushing stages, four sieves and conveyors.

\subsection{Topography of the quarries}

The topography of all the studied quarries is characterized by a large flat area bordered by steep quarry walls. In the natural stone quarry, this topography is the most pronounced since the height difference between the flat quarry bottom and the top of quarry walls was approximately $30 \mathrm{~m}$, whereas in the aggregate quarries (quarry 5 and 7) the elevation difference was approximately $10 \mathrm{~m}$.

The area of main interest is the flat area at the bottom of the quarry in the quarries $B$ and 5 . In the quarry 7 , the area of main interest is the flat area at the bottom of the quarry, as well as the area on the top of the next quarry wall at the DW direction. 
Table 2 Modelled situations and respective emission factors (EFs)

\begin{tabular}{|c|c|c|c|c|c|}
\hline $\begin{array}{l}\text { Modelling } \\
\text { situation ID }\end{array}$ & Dust source & $\begin{array}{l}\text { Production capacity of drill/ } \\
\text { crusher }\end{array}$ & $\begin{array}{l}\text { Dust source to which EF is } \\
\text { given }\end{array}$ & $\begin{array}{l}\text { Emission fac- } \\
\text { tor }\left(\mathrm{kg} \mathrm{PM}_{10} /\right. \\
\mathrm{tn})\end{array}$ & $\begin{array}{l}\text { Emission } \\
\text { factor (g } \\
\left.\mathrm{PM}_{10} / \mathrm{s}\right)\end{array}$ \\
\hline D1 & $\begin{array}{l}\text { Drilling in natural stone quarry } \\
\text { B }\end{array}$ & $\begin{array}{l}50 \mathrm{~m} / \mathrm{h} \\
\text { Stone block drilled dur- }\end{array}$ & Dry drilling & - & $0.504^{\mathrm{a}}$ \\
\hline D2 & $\begin{array}{l}\text { Drilling in natural stone quarry } \\
B\end{array}$ & $\begin{array}{l}\text { ing the measurements: } \\
25 \mathrm{~m} \times 8 \mathrm{~m} \times 6 \mathrm{~m}\end{array}$ & Dry drilling & - & $0.213^{\mathrm{a}}$ \\
\hline D3 & $\begin{array}{l}\text { Drilling in natural stone quarry } \\
\mathrm{B}\end{array}$ & $\begin{array}{l}\text { Distance between drill holes } \\
0.3 \mathrm{~m}\end{array}$ & Wet drilling & $4 \times 10^{-5 b}$ & 0.001549 \\
\hline \multirow[t]{4}{*}{ C5 } & Crushing in aggregate quarry 5 & $200 \mathrm{t} / \mathrm{h}$ & Crusher & $0.0012^{\mathrm{b}}$ & 0.0667 \\
\hline & & & Sieve & $0.0043^{b}$ & 0.23889 \\
\hline & & & Conveyor transfer point & $0.00055^{b}$ & 0.06112 \\
\hline & & & In total & & 0.36671 \\
\hline \multirow[t]{4}{*}{ C7 } & Crushing in aggregate quarry 7 & $200 \mathrm{t} / \mathrm{h}$ & Crusher & $0.0012^{b}$ & 0.0667 \\
\hline & & & Sieve & $4 \times 0.0043^{b}$ & $4 \times 0.23889$ \\
\hline & & & Conveyor transfer point & $4 \times 0.00055^{b}$ & $4 \times 0.06112$ \\
\hline & & & In total & & 1.26674 \\
\hline
\end{tabular}

EFs input are presented bolded

${ }^{\mathrm{a}}$ Ref [14]

${ }^{\mathrm{b}} \operatorname{Ref}[13]$

National coordinate systems and elevations were used in the model to create 3D surface in the AERMOD. Surface model was built via receptor points. The amount of points was tested with the AutoCAD Civil 3D (version 2016) by creating a surface model from receptor points. The 3D-surface model built in the AutoCAD was compared to the actual surface models of the quarries. Additional receptor points were added, if needed. The receptor points were also located in the same spots as the site measurements for all modelled quarries B (natural stone quarry), 5, and 7 (aggregate quarries). For the natural stone quarry, in total 177 receptor points, having coordinates and elevations were inputted into the AERMOD. For the aggregate quarries 5 and 7, in total 429 and 484 receptor points, respectively, were entered into the program.

Since the topography of the quarries is steep, it was modelled, how the changes in the topography settings affected the dispersion from the drilling. The additional models were made with settings of flat terrain, and flat and elevated terrain. Neither of these changes in the model settings showed any significance on the results.

\subsection{Meteorological parameters}

Data from the nearest National weather stations were applied. They located approximately $45 \mathrm{~km}$ to the southeast, $15 \mathrm{~km}$ to the south, and $40 \mathrm{~km}$ to the south from the quarry $B, 5$, and 7 , respectively. The meteorological data were purchased from the BREEZE Software company, and it needed no additional processing before entering into the modelling program.

The meteorological data of the actual date and hours of the day, when the site measurements occurred, were used in the modelling. The measurements and therefore also the models covered 3 to 5 -h periods. Modelling is usually applied for longer time periods, e.g. months or even years.

\subsection{Bruno}

Crushing and screening processes in the quarries 5 and 7 were simulated using Metso Minerals' Bruno Process Simulation software (from now on Bruno). The target was to estimate the amount of $0-0.063 \mathrm{~mm}$ fraction generated in the process. The simulation result was then compared to measured and calculated dust emissions to find out the correlation. The assumption is, that larger amount of dust fraction present induces higher dust emission.

Bruno is designed to predict both an individual machine performance and an entire process performance. The results reflect as close as possible the actual machine performance, because the calculation models are based on life size crusher and screen performance measurements. Using Bruno was appropriate, because process machines were mainly Metso products.

The machine performance key figures are throughput, product particle size distribution (PSD) and power consumption. The same key figures are also applied to process performance. In this case the special interest was to 
estimate the amount of $0-0.063 \mathrm{~mm}$ (also referred as fines) fraction in the final product.

The inputs for the calculation are (Table 3):

- feed material crushability and solid density

- feed PSD and tonnage

- machines settings

- real life process configuration

Crushability (\%) is a rock test [15] value, which indicates how difficult rock material is to crush. The scale is from 0 to $100 \%: 0 \%$ is uncrushable and $100 \%$ extremely easily crushable. Crushability below $30 \%$ is considered hard rock

Table 3 Bruno calculation process feed inputs for the quarries 5 and 7

\begin{tabular}{lllll}
\hline Quarry ID & $\begin{array}{l}\text { Crush- } \\
\text { ability } \\
(\%)\end{array}$ & $\begin{array}{l}\text { Solid } \\
\text { density } \\
\left(\mathrm{t} / \mathrm{m}^{3}\right)\end{array}$ & $\begin{array}{l}\text { Feed particle size } \\
\text { distribution (PSD) }\end{array}$ & Feeding $(\mathrm{t} / \mathrm{h})$ \\
\hline Quarry 5 & 35 & 2.70 & $0-400 \mathrm{~mm}$ coarse & 200 \\
Quarry 7 & 32 & 2.66 & $0-500 \mathrm{~mm}$ medium & 200 \\
\hline
\end{tabular}

and over $50 \%$ is soft rock. The required rock properties are physical instead of chemical or mineralogical.

Machines, machine settings and process configuration were observed on the sites, while making dust emission measurements. When estimating fines production, both selected crushers and process configuration as well as feed material behaviour have significant impact on the outcome. In the quarry 5 (Fig. 1) 0-32 mm final product was produced by simple two stage process.

In the quarry 7 (Fig. 2) 0-45 mm fraction was scalped out from the feed. The actual process set-up included four crushing stages. After four crushing stages, product 0-16 mm was further screened into 0-4 $\mathrm{mm}, 4-11 \mathrm{~mm}$ and $11-16 \mathrm{~mm}$ fractions. The final product screening was left out, because screening is not assumed to increase the total amount of fines.

From the perspective of process design, the amount of $0-0.063 \mathrm{~mm}$ produced depends on the number of crushing stages and the performance of individual crushers. The size reduction work in both processes is done by compressive crushers, which tend to produce relatively similar product PSD regardless of the feed PSD. There will be some fines in the product of each crusher. The amount of fresh

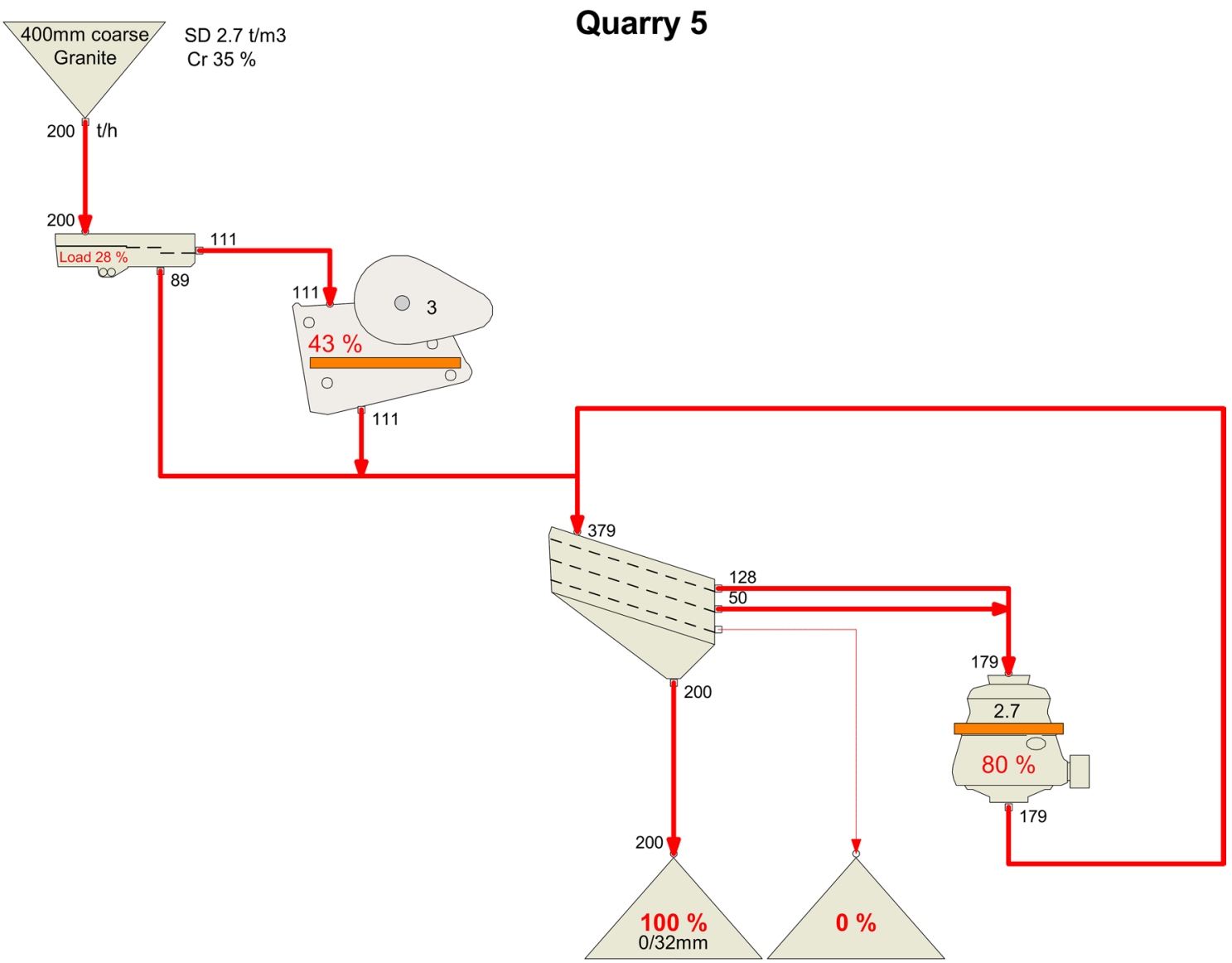

Fig. 1 The quarry 5 crushing and screening process flow. Two crushing stages, primary jaw crusher and secondary cone crusher 


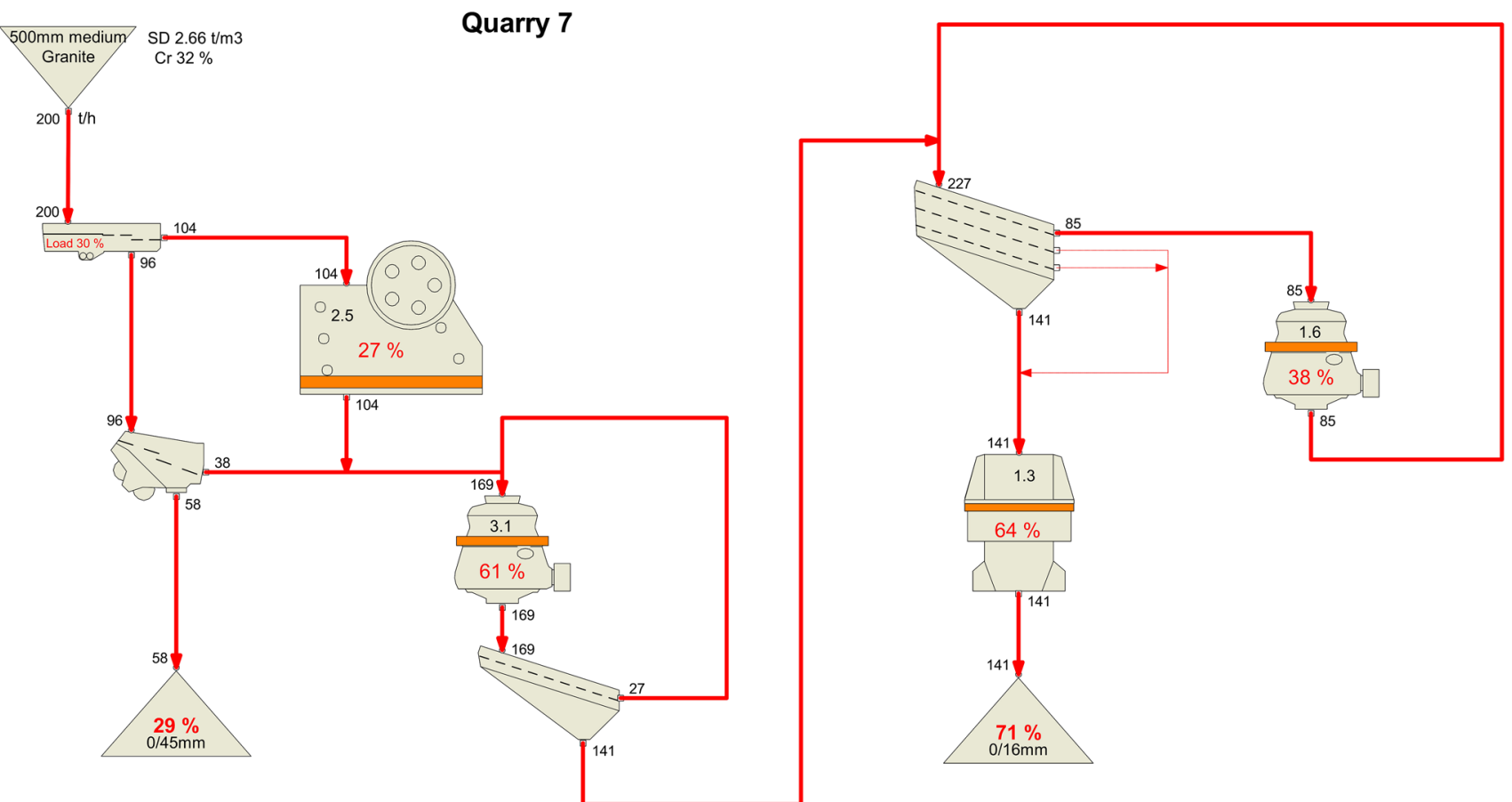

Fig. 2 The quarry 7 crushing and screening process flow. Four crushing stages, primary jaw crusher, secondary and tertiary cone crushers and quaternary horizontal shaft impactor

Table $40-0.063 \mathrm{~mm}$ fraction in the quarry 5 and 7 processes

\begin{tabular}{lll}
\hline & Quarry 5 & Quarry 7 \\
\hline Scalpings & & $1.4 \mathrm{t} / \mathrm{h}$ \\
Primary & $2.18 \mathrm{t} / \mathrm{h}$ & $0.78 \mathrm{t} / \mathrm{h}$ \\
Secondary & $5.23 \mathrm{t} / \mathrm{h}$ & $3.65 \mathrm{t} / \mathrm{h}$ \\
Tertiary & & $5.29 \mathrm{t} / \mathrm{h}$ \\
Quaternary & & $6.85 \mathrm{t} / \mathrm{h}$ \\
Total & $5.23 \mathrm{t} / \mathrm{h}$ & $8.25 \mathrm{t} / \mathrm{h}$ \\
\% of 0-0.063 mm in the final & $2.6 \%$ & $4.9 \%$ \\
product(s) & & \\
\hline
\end{tabular}

fines in a crusher product can be somewhat controlled by process design. By removing fines from the crusher feed PSD, the amount of new fines is effectively maximized. The more fines in the feed, the less new fines are produced. Considering crusher operation neither of the example processes was optimized to minimize fines generation. Also, the more crushing stages, the more new fines are potentially generated (see Table 4).

The relative and the absolute amount of $0-0.063 \mathrm{~mm}$ in the final product (Table 4) is higher in the quarry 7 applying four stage crushing process compared to results from the quarry 5 applying two crushing stages. If the fines in the scalpings in the quarry 7 are taken into account, the share of the $0-0.063 \mathrm{~mm}$ fraction in the process outputs is approximately double compared to the quarry 5. Based on the estimated fines content the dust emission at quarry 7 would potentially be higher.

Bruno results, considering the estimation of $\mathrm{PM}_{10}$ are only indicative. In the standard aggregate laboratory sieving analysis the smallest sieve size is $0.063 \mathrm{~mm}$ and PSD below $0.063 \mathrm{~mm}$ is unknown. To be able to estimate the potential dust emission of various processes, the amount of $0-0.01 \mathrm{~mm}$ is assumed to be directly proportional to the amount of $0-0.063 \mathrm{~mm}$.

\section{Results}

\subsection{Comparison of measured and modelled concentrations}

The hourly averages of the modelled $\mathrm{PM}_{10}$ results were compared to the hourly averages of the measured concentrations. Comparison was made with reference points, in other words the receptor points entered into the model, which corresponded the actual measurement points in the site (see Figure A1 in Online Resource A1). The focus was in DW direction dust retention.

The modelled results using the EF from Aatos [14] are 20 to 50 times higher compared to the measured concentrations from drilling. When applying the EF from US EPA 


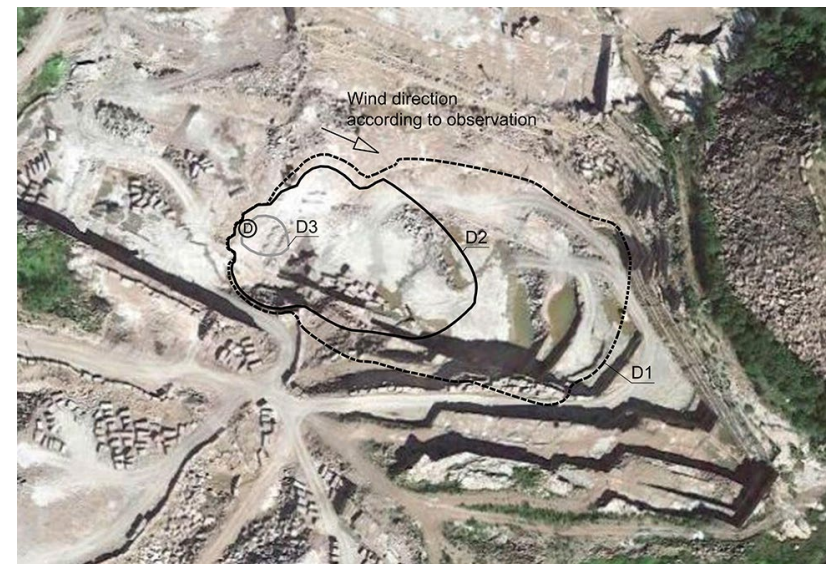

Fig. 3 Dust dispersion from the drilling during the measurement day 1. Modelled concentration contours of $50 \mu \mathrm{g} \mathrm{PM} / 1 \mathrm{~m}^{3}$ from the models D1, D2 and D3, dashed black line, solid black line, and solid grey line, respectively. (D) denotes drill. Aerial photograph: Google Earth Pro

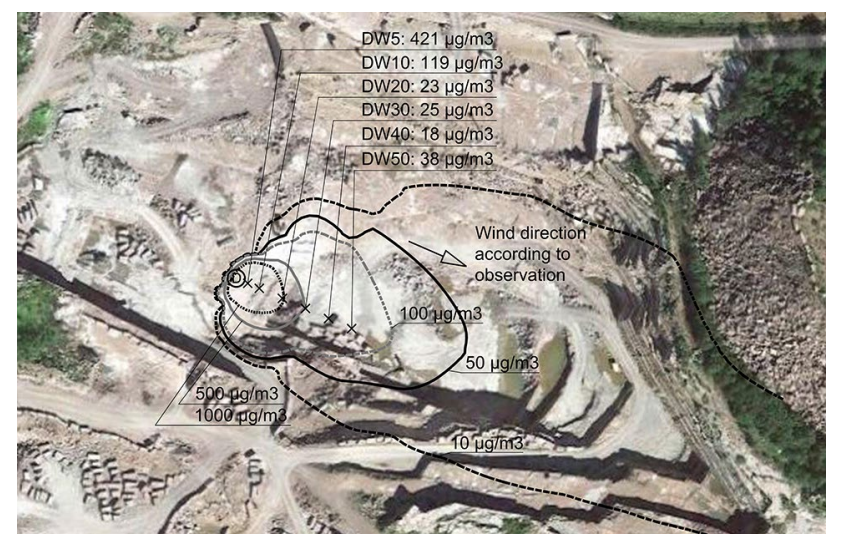

Fig. 4 Modelled concentration contours of the model D2 and the measured $\mathrm{PM}_{10}$ concentrations near the drilling. (D) denotes the drill. $X$ is the measurement location in the downwind (DW) direction. Aerial photograph: Google Earth Pro

[13], the modelled results are approximately $16 \times 10^{-3} \%$ in average of the measured concentrations. Figure 3 presents the modelled concentration contours of all three different modelled EFs of drilling (D1-D3).

Figure 4 shows the concentration contours of the model D2 of drilling and the measured dust concentrations during the measurement day 1 . The dust measurements were made in the DW direction and the distance from the drill is in metres.

The EF of the model C7 (quarry 7, four crushing stages), is nearly 3.5 times the EF of model C5 (quarry 5, two crushing stages). As can be seen in Figs. 1 and 2 the process in the quarry 7 had twice as many process machines providing number of potential emission

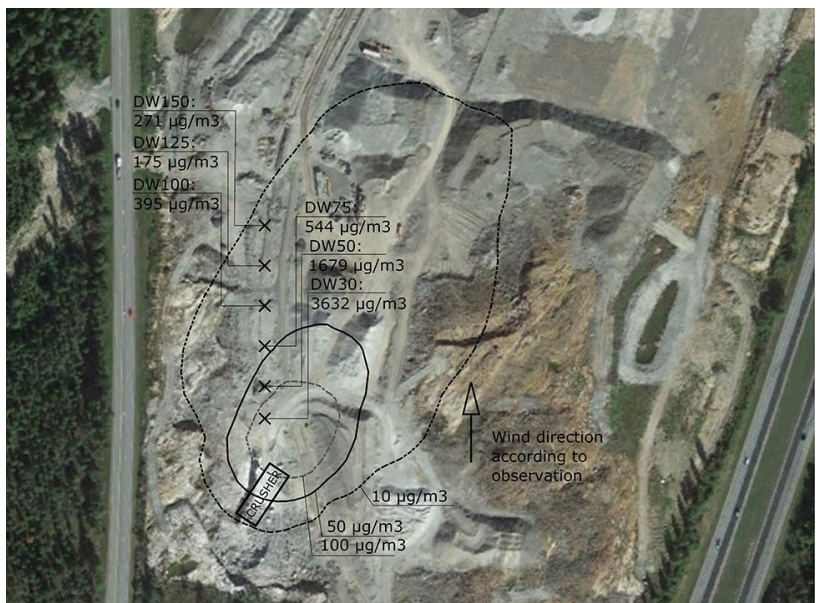

Fig. 5 Modelled concentration contours of the model C5 and the measured $\mathrm{PM}_{10}$ concentrations near two stages crushing. $X$ is the measurement location in the downwind (DW) direction. Aerial photograph: Google Earth Pro

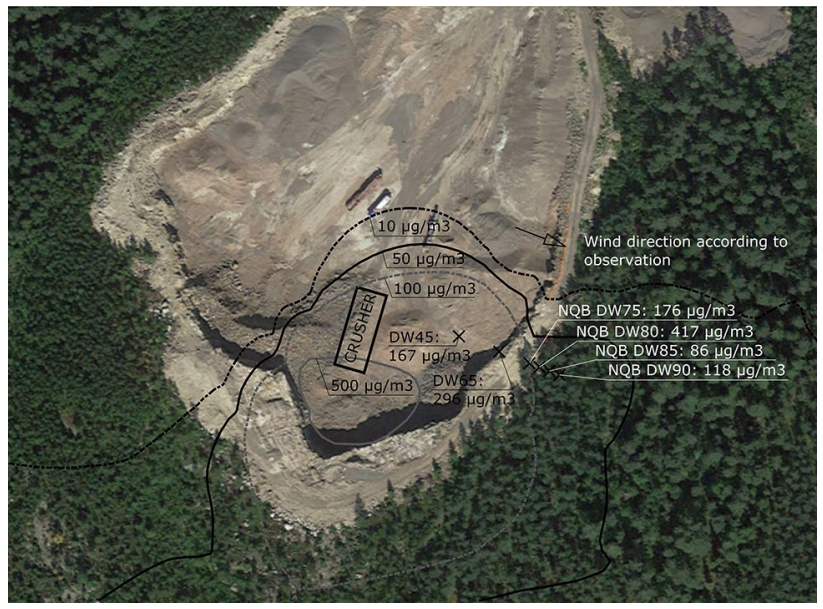

Fig. 6 Modelled concentration contours of the model C7 and the measured $\mathrm{PM}_{10}$ concentrations near four stages crushing. $X$ is the measurement location in the downwind (DW) direction. Aerial photograph: Google Earth Pro

sources. 3.5 times higher EF in the quarry 7 is in accordance with the Bruno calculations according to which the quarry 7 crushing process potentially produces twice as much $0-0.063 \mathrm{~mm}$ and $0-0.01 \mathrm{~mm}$ fractions compared to the process in the quarry 5 .

Concentrations modelled in the quarry 5 were on average only $5 \%$ of the measured ones, while dust produced during the crushing in the quarry 7 were roughly the same as the modelled, approximately $93 \%$ of measured ones. In Figs. 5 and 6 are presented the modelled concentration contours and the measured results in the quarry 5 and the quarry 7. 


\subsection{Model performance evaluation}

In Figs. 7 and 8 are presented the quantile-quantile plots (Q-Q plots) for drilling and crushing, respectively.

As it is seen in Figs. 7 and 8, the measured and modelled concentrations scatter in Q-Q plots. In Table 5 is compared the model performance in relation to the measured concentrations in more detail.

The coefficient of determination $R^{2}$ evaluates the ability of the model of describing the variability in the measurements independently of systematic variations. For dispersion modelling where concentrations often vary by several orders of magnitude, the geometric mean (MG) and the geometric variance (VG) are better for model performance evaluation, than the fractional bias (FB) and the normalized mean square error (NMSE) [16]. An MG greater than 1 implies that the model overestimates and an MG less than 1 that the model underestimates. As for the geometric mean bias, the geometric mean variance is recommended when the range of concentrations is wide, since it gives the same weight to pairs showing the same ratio, independently from the absolute value of the data.

\subsection{Effect of weather parameters}

Analysis of concentration variation according to changes in the weather parameters revealed, that the modelled concentrations were sensitive for altering weather parameters, whereas the measured concentrations mainly lacked reacting according to changes in the weather parameters.

The model assumed dust concentration to increase with increasing sensible heat flux ( $\mathrm{HO}$ : Conductive heat flux from the Earth's surface to the atmosphere) and reference wind speed (REF WS: wind speed at reference height of $10 \mathrm{~m}$ ). The measured dust concentrations of crushing also increased with increasing REF WS. Instead, the drilling showed slight decrease in the measured dust concentrations with increasing REF WS. The measured concentrations did not reflect any changes with changing $\mathrm{H} 0$.

With increasing relative humidity $(\mathrm{RH})$, the model assumed decreasing dust concentration. $\mathrm{RH}$ reflected no changes in the measured concentrations of drilling. Similar indicative change in the modelled dust concentrations in relation to $\mathrm{RH}$ was observed for the measured concentrations in the quarry 5, although the changes in $\mathrm{RH}$ were small in aggregate quarries. The model also assumed more pronounced dust concentration decrease with increasing distance compared to the measurements.

When viewing concentration variation of the modelled and measured concentrations of each examined hour, results varied. In the aggregate quarry 5 , the measured and modelled hourly dust concentrations caused by the crushing seemed to behave in opposite manner within the viewed time span: When the measured concentration decreased, the modelled concentration increased and

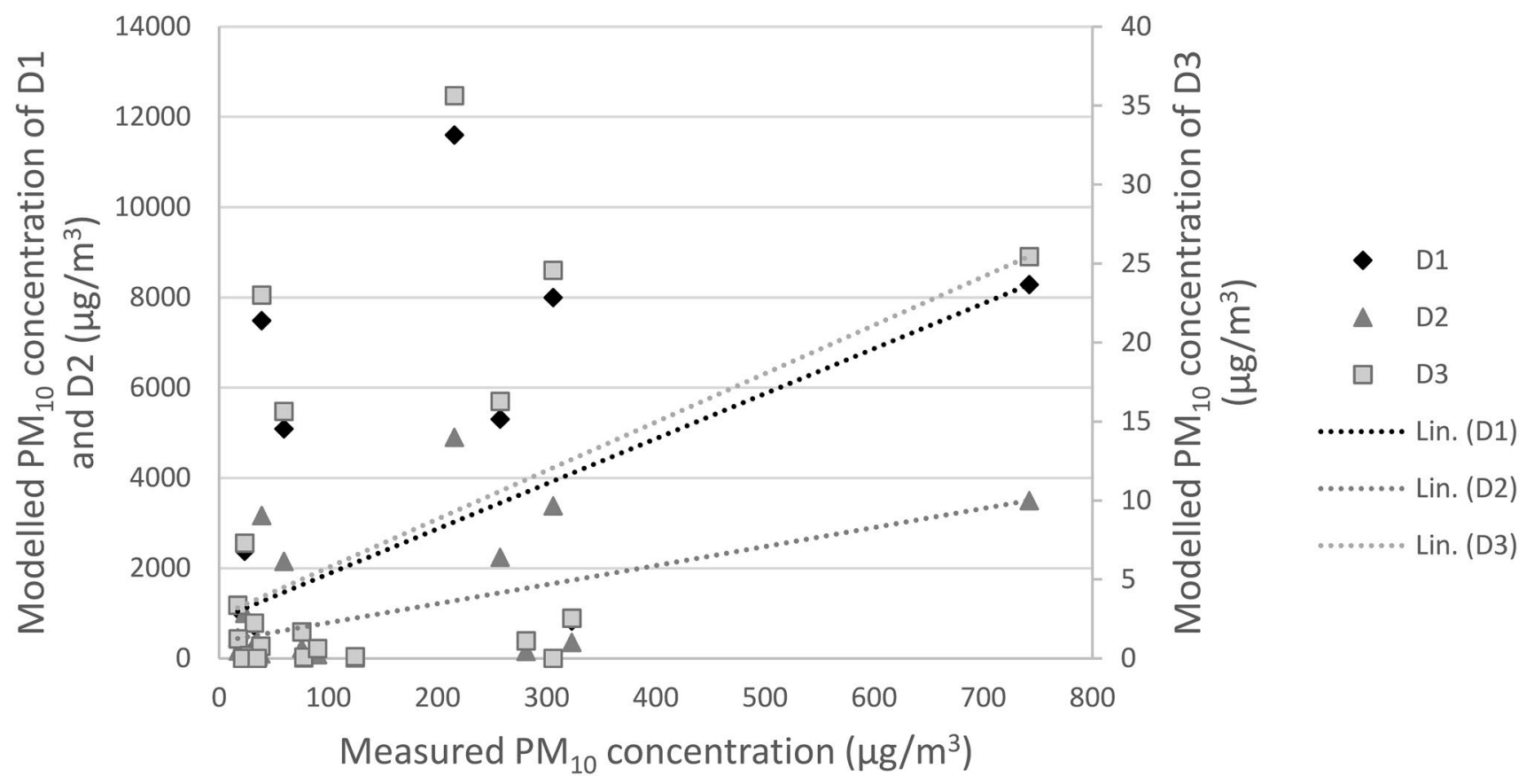

Fig. 7 Comparison of the modelled and measured $\mathrm{PM}_{10}$ concentrations for the drilling. Emission factors according to Aatos [14] (models D1 and D2, first $y$-axis) and according to US EPA [13] (model D3, second $y$-axis) 


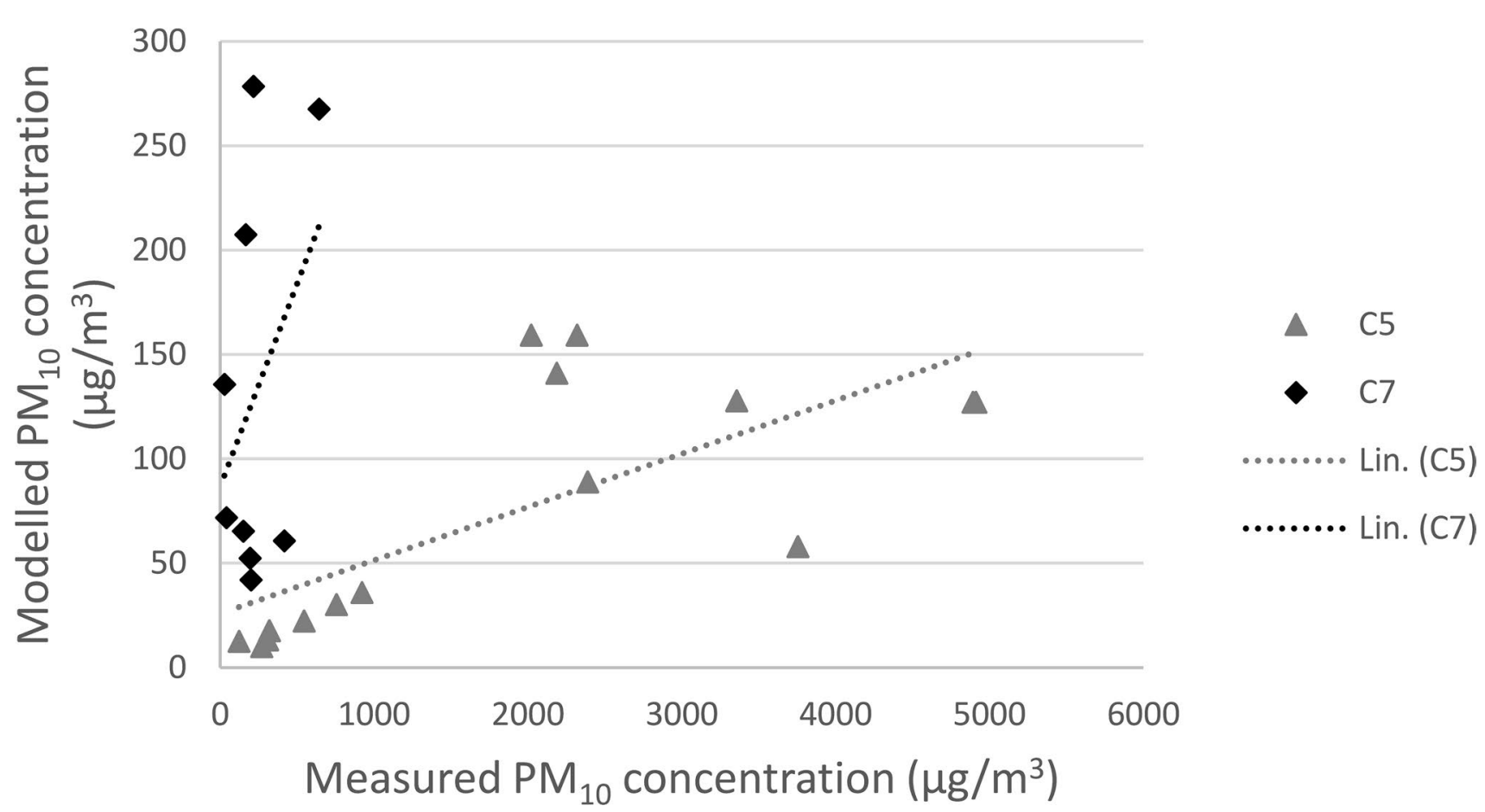

Fig. 8 Comparison of the modelled and measured $\mathrm{PM}_{10}$ concentrations of crushing in the aggregate quarries 5 and 7 . Emission factors according to US EPA [13]

Table 5 Comparison of the measured and modelled results

\begin{tabular}{|c|c|c|c|c|c|c|}
\hline Parameter & D1 & D2 & D3 & C5 & $\mathrm{C7}$ & $\begin{array}{l}\text { Perfect } \\
\text { value }^{a}\end{array}$ \\
\hline Slope of the linear regression $(m)$ & 9.99 & 4.22 & 0.031 & 0.026 & 0.19 & 1 \\
\hline Offset of the regression $(b)$ & 874.09 & 369.41 & 2.69 & 25.93 & 86.75 & 0 \\
\hline Coefficient of determination $\left(R^{2}\right)$ & 0.24 & 0.24 & 0.24 & 0.52 & 0.15 & 1 \\
\hline Coefficient of correlation $(r)$ & 0.49 & 0.49 & 0.49 & 0.72 & 0.39 & 1 \\
\hline Probability value $(p)$ & $4.85 \times 10^{-3}$ & 0.01 & $1.17 \times 10^{-3}$ & $1.77 \times 10^{-4}$ & 0.19 & 0 \\
\hline Geometric mean bias (MG) & 3.72 & 1.57 & 0.02 & 0.04 & 0.65 & 1 \\
\hline Geometric variance (VG) & $3.77 \times 10^{3}$ & $3.83 \times 10^{3}$ & $1.29 \times 10^{2}$ & 2.72 & 1.62 & 1 \\
\hline
\end{tabular}

a Value of parameter, when the measured and modelled concentrations are the same in all reference points

vice versa. Instead, in the aggregate quarry 7 , the measured and modelled concentrations partly reflected similar direction in changes between the hours examined. With drilling, both phenomena were observed. During the day 1 of drilling in the natural stone quarry $B$, the changes in concentration did not correlate between the measured and modelled results, whereas during the second day, the concentration changes aligned (Fig. 9).

Hourly dust concentrations of crushing in the summer varied between 30 and $650 \mu \mathrm{g} \mathrm{PM}_{10} / \mathrm{m}^{3}$, whereas in the wintertime the hourly concentration variation was from 900 to $2400 \mu \mathrm{g} \mathrm{PM} / 10 \mathrm{~m}^{3}$ at $65 \mathrm{~m}$ and $50 \mathrm{~m}$ distance DW direction from the crusher, respectively.
In the Online Resource A2 is presented in more detail the effect of weather conditions on the modelled concentrations. In the Online Resource Figure $A 2 / 1$ and $A 2 / 2$ is presented the hourly concentration contours of drilling during measurement day 1 and 2, respectively. In Figures $A 2 / 3$ and $A 2 / 4$ are the modelled hourly concentration contours of the crushing models $C 5$ and $C 7$, respectively.

\subsection{Site-specific emission factors}

All the previously determined EFs used in this study produced modelled concentrations different from the measured ones. Therefore, the site-specific EFs were determined 


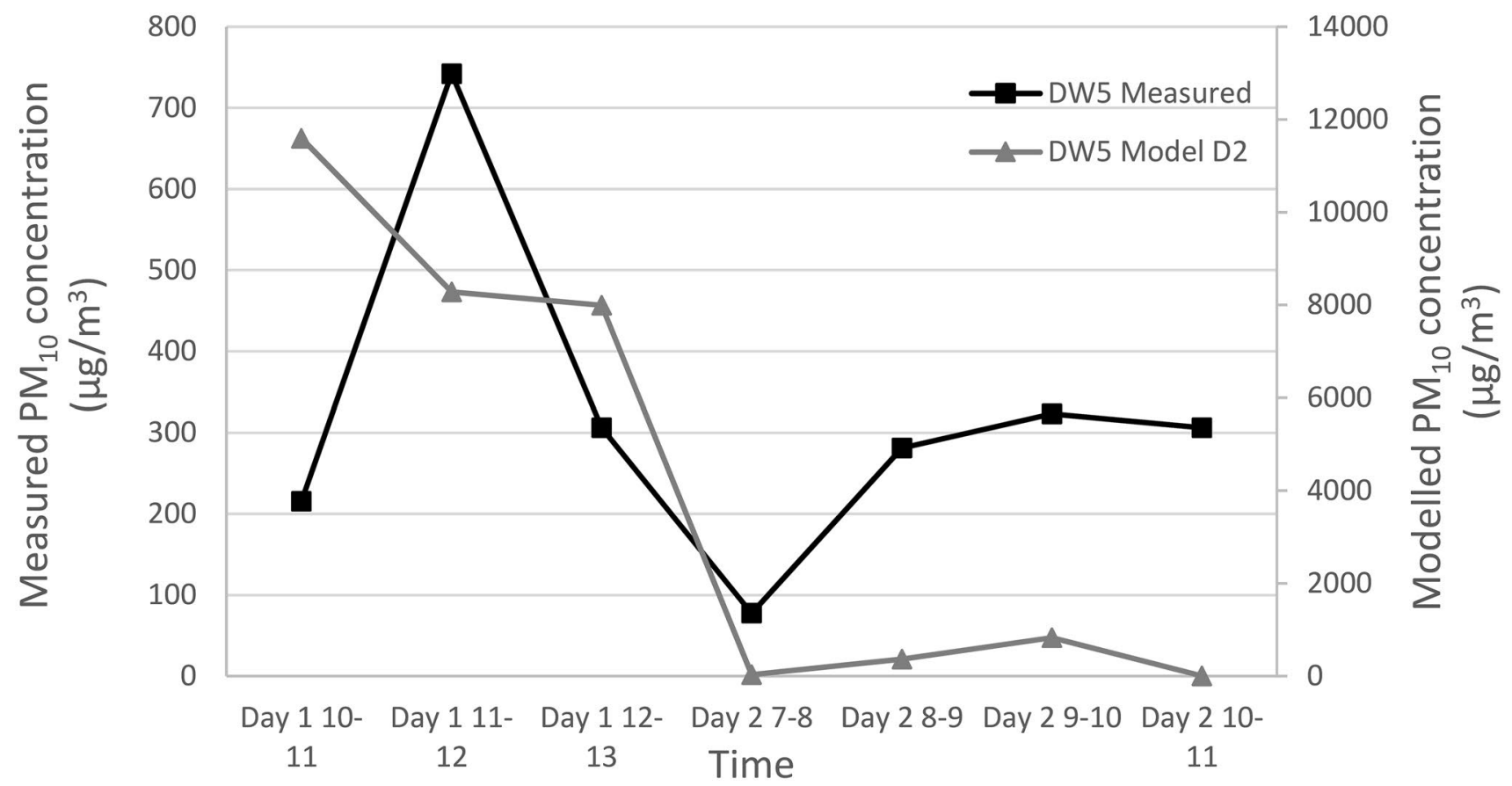

Fig. $9 \mathrm{PM}_{10}$ concentrations at $5 \mathrm{~m}$ downwind (DW) from the drill: Measured (first $y$-axis) and modelled (second $y$-axis)

for all the modelled quarries and were used to model the same situations as was modelled with EFs of US EPA [13] and Aatos [14].

The site-specific EFs were calculated using the average ratios of the difference between the modelled and measured concentrations. The ratio between the modelled and measured concentration of drilling were 100, 42 and 0.31 for models D1, D2 and D3, respectively. For the drilling, the ratios gained from all three modelled situations led to the same site-specific EF of drilling, which is $0.005 \mathrm{~g} / \mathrm{s}$.

For crushing in the quarry 5 , the ratio between the modelled and measured concentrations was 0.045. This leads to the site-specific EF of $8.15 \mathrm{~g} / \mathrm{s}$ for the crushing in the quarry 5 . For crushing in the quarry 7 , the ratio between the modelled and measured concentration was 0.934 , leading to the site-specific EF of $1.36 \mathrm{~g} / \mathrm{s}$ for the crushing in the quarry 7.

\subsection{Dust decay curves: measured versus predicted}

Exponential dust retention curves for $\mathrm{PM}_{10}$ were determined from the measurements in the aggregate quarry 7. Background concentration of $\mathrm{PM}_{10}$ is $16 \mu \mathrm{g} / \mathrm{m}^{3}$ [5]. The distance, where the background concentration is achieved according to the measurements, was approximately $340 \mathrm{~m}$ for the quarry 7.

The distance, where the dust concentration reaches the background concentration was calculated also for the modelled concentrations. Exponential dust decay curve was used. The distances, where the background concentration of $\mathrm{PM}_{10}$ is reached, are presented in Table 6.

As it is seen in Table 6, modelling assumes faster dust retention compared to the measurements, except in the quarry 5, where the modelled results from the site-specific EF predict slightly slower dust retention compared to the measurements.

\section{Discussion}

The EFs for drilling by Aatos [14] overestimated the dust concentration during the first measurement day, whereas on the second measurement day the modelled concentrations underestimated the concentration levels. This is due to the model's tendency to react more severely into the changes of weather, like the wind direction (see Online Resource A2 Figures A2/1 and A2/2). The measured concentrations showed significantly less alteration according to the weather parameters. Overestimation of the first day's predictions was significant, from 20 to 50 times. US EPA [13] EF for wet drilling underestimated the concentration, and the modelled concentrations were approximately $16 \times 10^{-3} \%$ of the measured ones. The underestimation in this case is expected, since the natural stone quarry $B$ applied dry drilling.

The EFs of US EPA [13] for crushing underestimated the dust concentration, when comparing the modelled $\mathrm{PM}_{10}$ concentrations to the measured ones during the 
Table 6 Distances where background concentration is achieved

Measured (m)
Modelled with EF from Aatos/US EPA for drilling and US EPA for crushing (m)
Modelled with site-specific EF determined in this study

(m)

\begin{tabular}{lllr}
\hline Drilling, D1/D2/D3 & $83^{\mathrm{a}}$ & $93 / 80 / 10$ & 26 \\
Crushing, C5 & $234^{\mathrm{b}}$ & 118 & 292 \\
Crushing, C7 & 338 & 130 & 124 \\
\hline
\end{tabular}

${ }^{\mathrm{a}} \operatorname{Ref}[3]$

${ }^{b} \operatorname{Ref}[5]$

wintertime. The underestimation of the model was significant, since the modelled concentrations were approximately $5 \%$ of the measured concentrations. Instead, the modelling reflected well the concentrations measured during the summer, when the modelled concentrations were, on average, approximately $93 \%$ of the measured ones. Tartakovsky et al. [9] observed modelled TSP concentrations being, on average, $42-81 \%$ of the measured ones.

According to Huertas et al. [17], the result of coefficient of determination $R^{2}>0.7$ can be considered to be high for modelling, which includes multiple sources of uncertainty in the process. In the aggregate quarry 5 , the $R^{2}$ is moderate $(>0.5)$, whereas in the other quarries, it is lower (approximately 0.2). In general, the modelled cases $C 5$ and C7 for crushing were in better agreement with the measurements compared to drilling.

Evaluation of the model performance reveals, that AERMOD is not able to model the dust concentration fluctuation inside the quarry area and its nearby neighbourhoods, when using the weather data form the National weather stations, even though AERMOD is previously reported to have better performance compared to other available modelling programs [e.g. 9, 10]. According to Tartakovsky et al. [9], on-site meteorological data were crucial for the reliable dispersion calculations in complex terrains. The smaller the distance between the sources, the meteorological stations and the receptors, the higher the chances are, that the topographical barriers do not affect the wind field and interfere with dispersion predictions [10]. Remote location of weather stations is assumed to be the main reason for the low performance of the model.

Tartakovsky et al. [9] concluded that it's a global-wise problem, that detailed emissions from quarries are generally not available and especially, emission information lack spatiotemporal accuracy. Dominant contributor to the variation between the modelled and measured concentrations was the uncertainty in the production rate on the specific hours in which the wind was blowing to the receptors [9]. In this study, the measurements were made in DW direction and the significant additional dust sources beside the measured drilling or crushing, were absent. Only occasional transportation of aggregates into storage piles was made during the crushing. Still, the model was partly unable to predict the measured concentrations. This was due to the differences in the weather parameters measured in the National weather stations and the weather parameters actually present inside the quarry area. It has also been reported in other studies, that the models are not fully capable of modelling the air flows within the quarry area and near its boundaries [e.g. 18, 19]. The steady state assumption of AERMOD prevents the model to responding to temporal and spatial variations in the meteorological conditions [20]. This also affected the difference between results.

The model reacted more severely into changes in the weather parameters, than what was observed during the measurements. The model's sensitivity to the weather changes was also observed by Tartakovsky et al. [9], who found large differences in the modelling results when using the meteorological data from different weather stations. They even concluded not to recommend the dispersion modelling under complex topography conditions, using the meteorological data from a non-in situ meteorology station. Despite this conclusion, Tartakovsky et al. [9] regarded the average estimates to be usable for assessing chronic exposure of people in the receptor sites, since the average model results were found to be much more reliable than the daily specific estimates. The longest time period (a month) was found to be the most reliable one, when evaluating model performance of AERMOD at different time scales by Zou et al. [21]. This is expected, since the dispersion can be assumed to occur with the prevailing wind directions, and therefore, modelling with long time period can be assumed to reflect this phenomenon. Modelling seems to be more applicable in point of view of chronic exposure, than short time dust events. When considering exposure and health effects, the dust dispersion modelling should be further studied taking particle size into consideration, since dust particles have been reported to have serious health effects and these effects depend on the particle size [e.g. 22-24]. 
Chakraborty et al. [25] determined EFs for iron ore mines. Their processes are considered to be comparable to the EFs of open-pit quarrying (drilling and crushing), since both process rock material. Chakraborty et al. [25] determined EF for drilling to be $0.343 \mathrm{~g} / \mathrm{s}$. This is nearly 70-fold compared to the site-specific EF for drilling determined in this study: $0.005 \mathrm{~g} / \mathrm{s}$.

Chakraborty et al. [25] defined an EF for overall mine and it was on average $4.721 \mathrm{~g} / \mathrm{s}$, which is approximately same order of magnitude as the site-specific EFs determined for the aggregate production (crushing) in this study: $8.15 \mathrm{~g} / \mathrm{s}$ for crushing in the quarry 5 and $1.36 \mathrm{~g} / \mathrm{s}$ for crushing in the quarry 7 .

The significantly larger site-specific EF in the quarry 5 ( $8.15 \mathrm{~g} / \mathrm{s}$ for two stages crushing) compared to site-specific EF in the quarry 7 ( $1.36 \mathrm{~g} / \mathrm{s}$ for four stages crushing) is in contradiction with the EFs of US EPA [13] and previous observations that the increase in number of crushing stages increases the amount of dust produced during the crushing [e.g. 5, 26]. Also, Bruno calculations support these previous findings. This contradiction in the aggregate quarries is supposed to be a consequence of different climatic conditions, since there were no significant differences in the crushing circuit compilation besides the number of stages applied. The temperature and the wind speed were different in the aggregate quarries 5 and 7 during the measurement, but the main reason for the difference is assumed to be a consequence of the winterand summertime weather conditions. During the wintertime, the ground inversion (air is cooled by contact with a colder surface until it becomes cooler than the overlying atmosphere) is typical and then conditions are stable. These stable conditions prohibit particles to mix into large air masses. In the summer the mixing is more efficient, because sun produces enough heat to erode the inversion. Therefore, the measured concentrations were lower during the summertime compared to the wintertime, due to the diluting effect of more efficient mixing of dust particles into larger air masses. Since the model reflected well the dust dispersion from crushing during the summertime, it seems that AERMOD is not capable of modelling the effect of the wintertime inversion, trapping the dust particles to remain near the ground and not allowing mixing of particles into higher atmospheric layers.

The difference in the concentration levels between the modelled results of the previously determined EFs and the measured $\mathrm{PM}_{10}$ values reveals that the EFs should take into account more variables than only the process of producing dust, as was suggested by Chakraborty et al. [25] and Bruce et al. [27]. As noted by US EPA [13], the moisture content of the material processed can have a substantial effect on the emissions. This effect is evident throughout the processing operations, where the surface wetness causes fine particles to agglomerate on or to adhere to the faces of larger pieces of rock, suppressing the dust formation [13]. Yet, this is not considered when determining EFs by US EPA [13].

Ghannam and El-Fadel [28] found significant differences when determining EFs for modelling from US EPA and from European Environment Agency (EEA). Also, this difference between the results of the respected organizations, shows that determining EFs still needs more research, before modelling reaches adequate reliability of predicting actual conditions near the dust sources. The modelled results cannot be more reliable, than the initial data fed into the modelling program.

The distances, where the background concentration of $\mathrm{PM}_{10}$ is achieved according to the measurements, was $340 \mathrm{~m}$ in the aggregate quarry 7 . This is the same order of magnitude, $350 \mathrm{~m}$, as reported previously for Finnish quarries by Sairanen and Rinne [5]. Previous measurements [5] were made during the winter and resuspension was minimal due to snow cover on the ground, whereas measurements in aggregate quarry 7 were made during the summer, when resuspension from quarry surface may appear. Nevertheless, same order of magnitude in the distances where background concentration is achieved imply, that resuspension of $\mathrm{PM}_{10}$ from the quarry surface was not significant when measuring in the quarry 7 .

Modelling results suggest faster dust retention compared to measurements. Modelling with EFs defined by US EPA [13] predicted that the background concentration is achieved at distances of $118 \mathrm{~m}$ in the quarry 5 and $130 \mathrm{~m}$ in the quarry 7 , which is approximately $35 \%$ of the distance needed to reach the background concentration according to the measured results by Sairanen and Rinne [5]. The site-specific EFs calculated in this study estimated that the background concentration is reached at $292 \mathrm{~m}$ and at $124 \mathrm{~m}$ from crushing in the quarries 5 and 7, respectively.

\section{Conclusions}

The comparison between the measured and the modelled dust concentrations showed, that the model AERMOD reacted more to changes in the weather conditions, whereas the measurements showed no significant changes. AERMOD was not able to predict hourly concentration fluctuation of the time span examined in this study. Main reason for this is assumed to be the lack of on-site meteorological data. Therefore, future studies comparing the measured and modelled dust concentrations near the dust source, are recommended to utilize weather data monitored on-site.

AERMOD assumes more pronounced dust retention with distance compared to the measurements. According 
to the modelled dust dispersion of crushing, the model predicted the background concentration to be achieved approximately at $65 \%$ shorter distance compared to the results gained from the measurements.

The emission factors (EFs) determined for drilling either overestimated (EF determined by Aatos [14]) or underestimated (EF determined by US EPA [13]) the dust concentration. The EF of dry drilling needs further research to obtain more realistic modelling results to reflect better the measured concentrations, since existing EFs provide highly varying results.

Modelling with AERMOD and using the EF determined by US EPA for crushing, predicted well the dust dispersion near the dust source during the summer, but the model was unable to predict the high dust concentration during the wintertime. This is suggested to be a consequence of ground inversion and more stable climatic conditions compared to the summer. This caused a significant underestimation of the modelled dust concentrations, compared to the measured ones, since the ground inversion trapped the dust particles to remain near the ground. According to these results, modelling is applicable to aggregate quarries operating during unstable (non-inversion) meteorological conditions. Usage of on-site weather parameters is recommended to gain more reliable results.

Acknowledgements Open access funding provided by Aalto University. Prof. Mikael Rinne and Dr. Olavi Selonen are thanked for their valuable comments on the manuscript. Metso Minerals is thanked for allowing the usage of Bruno in this study. FCG Finnish Consulting Group Oy is acknowledged for the usage of Osiris nephelometers in measurements. Two anonymous reviewers are thanked for their critical comments which considerably improved the quality of manuscript.

\section{Compliance with ethical standards}

Conflict of interest The authors declare that they have no conflict of interest.

Open Access This article is licensed under a Creative Commons Attribution 4.0 International License, which permits use, sharing, adaptation, distribution and reproduction in any medium or format, as long as you give appropriate credit to the original author(s) and the source, provide a link to the Creative Commons licence, and indicate if changes were made. The images or other third party material in this article are included in the article's Creative Commons licence, unless indicated otherwise in a credit line to the material. If material is not included in the article's Creative Commons licence and your intended use is not permitted by statutory regulation or exceeds the permitted use, you will need to obtain permission directly from the copyright holder. To view a copy of this licence, visit http://creativecommons .org/licenses/by/4.0/.

\section{References}

1. Petavratzi E, Kingman SW, Lowndes IS (2005) Particulates from mining operations: a review of sources, effects and regulations. Miner Eng 18:1183-1199

2. Sairanen M, Rinne M, Selonen O (2018) A review of dust emission dispersions in rock aggregate and natural stone quarries. Int J Min Reclam Environ 32(3):196-220

3. Sairanen M, Selonen O (2018) Dust formed during drilling in natural stone quarries. Bull Eng Geol Environ 77:1249-1262

4. Office of the Deputy Prime Minister (2005) Mineral policy statement 2: controlling and mitigating the environmental effects of minerals extraction in England. Office of the Deputy Prime Minister, London

5. Sairanen M, Rinne M (2019) Dust emission from crushing of hard rock aggregates. Atmos Pollut Res 10:656-664

6. SFS-EN 12341 (2014) Ambient air. Standard gravimetric measurement method for the determination of the $\mathrm{PM}_{10}$ or $\mathrm{PM}_{2,5}$ mass concentration of suspended particulate matter. Finnish Standards Association SFS, The European Standard EN 12341:2014 has the Status of a Finnish National Standard

7. Holmes NS, Morawska L (2006) A review of dispersion modelling and its application to the dispersion of particles: an overview of different dispersion models available. Atmos Environ 40:5902-5928

8. Sivacoumar R, Raj SM, Chinnadurai SJ, Jayabalou R (2009) Modelling of fugitive dust emissions and control measures in stone crushing industry. J Environ Monit 11:987-997

9. Tartakovsky D, Broday DM, Stern E (2013) Evaluation of AERMOD and CALPUFF for predicting ambient concentrations of total suspended particulate matter (TSP) emissions from a quarry in complex terrain. Environ Pollut 179:138-145

10. Tartakovsky D, Stern E, Broday DM (2016) Dispersion of TSP and $\mathrm{PM}_{10}$ emissions from quarries in complex terrain. Sci Total Environ 542:946-954

11. Venkatram A, Isakov V, Yuan J, Pankratz D (2004) Modelling dispersion at distance of meters from urban sources. Atmos Environ 38:4633-4641

12. US EPA (2018) Air quality dispersion modelling — preferred and recommended models. https://www.epa.gov/scram/air-quali ty-dispersion-modeling-preferred-and-recommended-model s. Accessed 18 Mar 2019

13. US EPA (2004) AP42, mineral products industry. 11.19.2 Crushed stone processing and pulverized mineral processing. Fifth edition. http://www.epa.gov/ttn/chief/ap42/ch11/final/c11s1902. pdf. Accessed 28 Oct 2015

14. Aatos S (2003) Luonnonkivituotannon pölypäästöt. Dust emissions in natural stone production. In: Aatos S (ed) Luonnonkivituotannon elinkaaren aikaiset ympäristövaikutukset. Environmental effects in natural stone production life cycle. Helsinki, Ympäristöministeriö, pp 120-127 (In Finnish with an English summary)

15. NF P-18-579 (1990) Essai d'abrasivité et de broyabilité des roches et granulats. Aggregates-abrasiveness and grindability test. French Standardization Association

16. Chang JC, Hanna SR (2004) Air quality model performance evaluation. Meteorol Atmos Phys 87:167-196

17. Huertas Jl, Huertas ME, Izquierdo S, González ED (2012) Air quality impact assessment of multiple open pit coal mines in northern Colombia. J Environ Manag 93:121-129

18. Lowndes IS, Silvester SA, Kingman SW, Hargreaves DM (2008) The application of an improved multi-scale computational modelling techniques to predict fugitive dust dispersion and deposition within and from surface mining operations. In: 12th 
U.S./North American mine ventilation symposium, Wallace ed., ISBN 978-0-615-20009-5

19. Silvester SA, Lowndes IS, Hargreaves DM (2009) A computational study of particulate emissions from an open pit quarry under neutral atmospheric conditions. Atmos Environ 43:6415-6424

20. Stovern M, Felix O, Csavina J, Rine KP, Russell MR, Jones RM, King M, Betterton EA, Sáez AE (2014) Simulation of windblown dust transport from a mine tailings impoundment using a computational fluid dynamics model. Aeolian Res 14:75-83

21. Zou B, Zhan FB, Wilson JG, Zeng Y (2010) Performance of AERMOD at different time scales. Simul Model Pract Theory 18:612-623

22. Pope CA III (2007) Mortality effects of longer term exposure to fine particulate air pollution; review of recent epidemiological evidence. Inhal Toxicol 19(Suppl. 1):33-38

23. US EPA (2013) Air \& radiation, six common pollutants, particulate matter PM, health. http://www.epa.gov/airquality/particlepo Ilution/health.html. Accessed 3 Apr 2014

24. Tian G, Wang J, Lu Z, Wang H, Zhang W, Ding W, Zhang F (2019) Indirect effect of $\mathrm{PM}_{1}$ on endothelial cells via inducing the release of respiratory inflammatory cytokines. Toxicol In Vitro 57:203-210
25. Chakraborty MK, Ahmad M, Singh RS, Pal D, Bandopadhyay C, Chaulya SK (2002) Determination of the emission rate from various opencast mining operations. Environ Model Softw 17:467-480

26. Petavratzi E, Kingman SW, Lowndes IS (2007) Assessment of the dustiness and the dust liberation mechanisms of limestone quarry operations. Chem Eng Process 46:1412-1423

27. Bruce J, Smith J, Datson H, Fowler M (2016) Modelling dust emissions from a source using dust monitoring and meteorological data. J Environ Prot 7:467-472

28. Ghannam K, El-Fadel M (2013) Emissions characterization and regulatory compliance at an industrial complex: an integrated MM5/CALPUFF approach. Atmos Environ 69:156-169

Publisher's Note Springer Nature remains neutral with regard to jurisdictional claims in published maps and institutional affiliations. 